\title{
PENDAMPINGAN TPCK: TEKNOLOGI, PEDAGOGI DAN PENGETAHUAN BAGI PENINGKATAN KOMPETENSI GURU SD DI KECAMATAN KEBUMEN
}

\author{
Kartika Chrysti Suryandari $^{1}$, Rokhmaniyah ${ }^{2}$, Wahyudi $^{3}$, M. Chamdani ${ }^{4}$, Joharman $^{5}$ \\ ${ }^{12345}$ Universitas Sebelas Maret \\ Corresponding email:kartika@ fkip.uns.ac.id
}

\begin{abstract}
ABSTRAK
Guru yang profesional di era revolusi industri 4.0 harus mampu mengintegrasikan pemanfaatan teknologi dan meningkatkan kompetensi guru perlu dilakukan pendampingan Technological Pedagogical Content Knowledge (TPCK). Tujuan Program Kemitraan Masyarakat adalah 1) Pendampingan penguasaan literasi Technological Knowledge (TK), 2) literasi Content Knowledge (CK), 3) penguasaan literasi Pedagogical Knowledge (CK) bagi calon guru SD. Manfaat pengabdian bagi guru SD mengalami pengembangan dan peningkatan berpikir secara kritis, analitik, mengevaluasi informasi, pemecahan masalah, dan penguasaan TPCK. Metode pengabdian partisipatif kelompok dan individu, sosialisasi, pelatihan dan pendampingan, penerapan dan monitoring. PKM dilaksanakan dengan mitra SDN 1 Kutosari pada tanggal 2-4 Juli 2020, dan diikuti 20 orang guru perwakilan dari beberapa SD di kecamatan Kebumen. Hasil kegiatan pengabdian masyarakat peserta antusias dan aktif mengikuki kegiatan sampai selesai. Peserta mengaplikasikan teknologi google phet simulation, pemantapan materi 5 mata pelajaran dan pembuatan soal HOTs. Kesimpulan kegiatan pendampingan TPCK sangat bermanfaat bagi pembelajaran di SD khususnya di masa pandemic covid 19.
\end{abstract}

Kata kunci: TPCK, literasi, kompetensi, guru SD

\begin{abstract}
Teachers who are professional in the era of the industrial revolution 4.0 must be able to integrate technology and improve teacher competency. The objectives of the Community Partnership Program are 1) Assistance in mastering the mastery of Technology Knowledge literacy, 2) Knowledge Content literacy, 3) Pedagogical Knowledge literacy mastery $(C K)$ for elementary teacher candidates. The benefits of service for elementary school teachers increase the development and increase critical thinking, analytics, recovering information, solving problems, and mastery of TPCK. Methods of participatory group and individual service, outreach, training and assistance, implementation and monitoring. The PKM was conducted with SDN 1 Kutosari partners on 2-4 July 2020, and was attended by 20 representative
\end{abstract}


teachers from several elementary schools in Kebumen sub-district. Results Community service activities of the enthusiastic and active participants followed the activity to completion. Participants apply google phet simulation technology, stabilize 5 subject matter and create HOTs questions. Conclusions TPCK assistance activities are very useful for learning in special elementary schools during the pandemic 19.

Keywords: TPCK, literacy, competence, elementary school teachers

\section{DOI: https://dx.doi.org/10.20961/dedikasi.v2i2.45226}

\section{PENDAHULUAN}

Era revolusi industri 4.0 mengintegrasikan pemanfaatan teknologi dan internet yang mempengaruhi kehidupan manusia pada dunia usaha, industri perilaku masyarakat dan pendidikan. Karakteristik di era revolusi industri meliputi digitalisasi, optimasi, produksi, otomasi dan adaptasi, interaksi antara manusia dengan mesin serta penggunaan teknologi informasi (Afandi \& Sajidan (2017). Pada abad 21 pengertian literasi mencakup keterampilan berpikir, menggunkan sumber pengetahuan dalam bentuk cetak, visual, digital dan auditori. Literasi teknologi merupakan kemampuan memahami kelengkapan teknologi untuk berkomunikasi, memecahkan masalah dalam pembelajaran. Salah satu upaya untuk meningkatkan kualitas pembelajaran maka seorang guru SD seharusnya mempunyai kompetensi di bidang pedagogis, profesionalisme, sosial dan kepribadian. Keempat kompetensi tersebut tertuang dalam UU No 14 Tahun 2005 tentang Guru dan Dosen. Menurut Shulman 1987, bahwa seorang guru harus memahami ranah pengetahuan ilmu mengajar (paedagogy), penguasaan materi/subjek (content) pembelajaran, dan pengetahuan teknologi (technology). Ketiga ranah harus dikuasai guru sehingga pembelajaran lebih bermakna. Dalam mengajarkan materi tidak sekedar transfer pengetahuan saja, namun aspek keterampilan proses, kognitif, dan afektif harus melebur dalam pembelajaran.

Penguasaan materi/subjek (content) mencakup fakta, konsep, prinsip dan teori. Cara mengajar dan memecahkan masalah pada pembelajaran serta pemanfaatan teknologi harus dikuasai oleh guru. Oleh karena itu pengetahuan materi subjek dengan dukungan teknologi sangat mendukung dalam pembelajaran. PCK merupakan wawasan akademik yang selalu berkembang terus menerus sesuai perkembangan jaman. Menurut Mishra \& Koehler, 2009 bahwa mengajar yang baik ada keterpaduan dan interaksi antara konten dalam hal ini materi pedagogi dan teknologi. Menurut Shulman 1986, kompetensi guru harus menguasai kombinasi pedagogical knowledge dan content materi subjek didukung media teknologi. Ketiga komponen tersebut dilaksanakan dalam pembelajaran dengan keterpaduan yang saling bervariasi untuk menghasilkan pembelajaran yang efektif 
dan bermakna. Guru harus menguasai materi subjek Content knowledge (CK) dalam pembelajaran, termasuk teori, konsep, ide dll. Pengetahuan materi harus mendalam agar tidak terjadi miskonsepsi pada siswa. Penguasaan teknologi khususnya ICT yang terintegrasi dalam materi yang memberi kesempatan siswa untuk aktiv, berpikir tingkat tinggi, konstruktivisme sehingga pembelajaran lebih bermakna (Jimoyiannis. 2010).

Menurut Kohler dan Misrah, (2009) menyatakan bahwa Content Knowledge (CK) seorang guru harus menguasai materi pembelajaran. Shulman (1986) menyatakan penguasaan materi meliputi konsep, teori, kerangka kerja di laboratorium dengan metode ilmiahnya. Pembelajaran bersifat inkuiri yang seharusnya dipahami guru secara mendalam bagaimana konsep-konsep dalam IPA itu terbentuk. Komponen Content Knowledge (CK) ini sesuai dalam PP No. 74 tahun 2008 pasal 3 ayat 2 yang isinya materi yang akan disampaikan kepada siswa harus dikuasai guru tentang keluasan dan kedalamanya serta keterkaitannya sehingga siswa lebih mengerti. Seorang guru harus dapat mengorganisasikannya dengan tepat baik dari segi kompleksitasnya (dari yang mudah kepada yang sulit, dari yang konkret kepada yang kompleks) maupun dari segi keterkaitannya (dari yang harus lebih awal muncul sebagai dasar bagi bagian berikutnya) sehingga pembelajaran bermakna.

Mishra dan Koehler (2010) menyatakan bahwa: "Pedagogical Knowledge refers to the method and proses of teaching and includes knowledge in classroom management, assessment, lesson plan development, and student learning”. Guru hendaknya menguasai proses atau metode mengajar dalam pembelajaran yaitu kompetensi yang hendak dicapai, tujuan pembelajaran, strategi mengajar, keterampilan manajemen kelas, rencana pembelajaran, evaluasi dan penilaian. Guru dengan Pedagogical Knowledge yang mendalam memperhatikan bagaimana siswa menyusun pemikiranya tentang materi pembelajaran, keterampilan prosesnya, dan mengembangkan sikap ilmiah. Dengan kata lain bahwa Pedagogical Knowledge memerlukan pemahaman kognitif, sosial dalam pengembangan teori pembelajaran dan penerannya pada siswa selama di kelas.

TPCK terdapat beberapa komponen yang saling berhubungan yaitu perpaduan antara Technology Knowledge (TK), Content Knowledge (CK) dan Pedagogical Knowledge (PK). Menurut Shulman (1986) bahwa TPCK merupakan cara atau berbagai strategi penyampaian materi kepada siswa. Materi yang disampaikan harus disesuaikan dengan tingkat pemahaman dan karakteristif siswa SD. Alternatif strategi pengajaran pada setiap konsep dengan analogi atau metafora sebagai cara untuk mengefektifkan pembelajaran. Pengalaman tentang bagaimana mengajar konten tertentu dengan cara khusus agar pemahaman siswa tercapai. Bentuk TPCK bagi setiap guru mempunyai karakteristik tertentu tergantung gaya mengajar, materi subjek konten dan pengalaman mengajar. Disamping itu juga karakteristik siswa yang sudah terbiasa dengan teknologi dalam kehidupan-sehari. Dengan demikian dapat disimpulkan bahwa TPCK bisa sama untuk beberapa guru 
atau berbeda guru lainya. Menurut Schneider and Plasman, (2011) komponen TPCK terdiri dari 1) orientasi mengajar, 2) cara berpikir tentang, 3) Strategi pembelajaran, 4) kurikulum, dan 5) assement.

TPCK guru sangat penting untuk menciptakan pembelajaran yang bermanfaat bagi siswa. Kemampuan guru matematika mengorganisasikan pembelajaran, penguasaan atas konsep-konsep yang diajarkan dan keterkaitan materi ajar dengan kehidupan nyata siswa adalah sebagian kecil dari hal-hal yang perlu dimiliki guru di dalam membelajarkan materi.

Dalam rangka untuk mendukung Universitas Sebelas Maret (UNS) menjadi Research University maka pengabdian kepada masyarakat sangat penting sebagai sarana untuk meningkatkan kualitas pembelajaran dan pengajaran. Prosedur penelitian dan hasilnya dapat digunakan untuk mendapatkan pembelajaran dan pengajaran yang efektif bagi pengajar dan peserta didik khususnya di Sekolah Dasar.

Menurut Standar Nasional Pendidikan Tinggi bahwa lulusan PGSD harus mempunyai kompetensi menguasai materi/konten sains dan cara mengajarkannya yang lebih dikenal dengan istilah Pedagogical Content Knowledge (PCK). Hasil penelitian Suryandari (2015) mendiskripsikan calon guru SD harus memenuhi kelima komponen Pedagogical Content Knowledge (PCK) yaitu 1) pemahaman tentang karateristik anak, 2) pemahaman kurikulum, 3) penguasaan materi, 4) pemahaman cara mengajar dan 5) pemahaman cara menilai.

Pengabdian ini mengacu pada RIP UNS tahap pengembangan sistem inovasi, bahwa mulai tahun 2020 hingga tahun 2024 UNS telah memasuki masa konsolidasi dalam sistem inovasi riset terfokus yang indikator pokoknya adalah aktivitas dan dinamika yang terencana dan terkelola dalam manajemen Research Group (RG).

\section{METODE KEGIATAN}

\section{Tempat Pelaksanaan Program}

Program pengabdian masyarakat ini dilaksanakan di SDN 1 Kutosari Kabupaten Kebumen dengan peserta guru-guru SD se gugus Kepatihan, Kebumen

\section{Prosedur Pelaksanaan Program}

Tahap: Identifikasi produk \& Sosialisasi

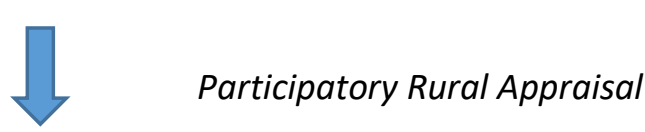

Tahap:

Produksi \& Evaluasi

Tahap: Praktek \& Pendampingan 
Gambar 1. Prosedur pengabdian masyarakat pendampingan TPCK bagi guru-guru SD

Pelaksanaan program pengabdian masyarakat menggunakan metode Participatory Rural Appraisal (PRA) atau Pemahaman Partisipatif Kondisi pedesaan (PRA) merupakan pendekatan dan metode yang memungkinkan masyarakat secara bersama-sama menganalisis masalah kehidupan untuk merumuskan perencanaan dan kebijakan secara nyata. PRA melibatkan masyarakat untuk saling berbagi, meningkatkan dan menganalisis pengetahuan tentang kondisi serta membuat rencana dan tindakan nyata (Chambers, 1996). Prinsip dasar yang harus dipenuhi dalam metode PRA yaitu keterlibatan semua anggota kelompok, berbagi pengalaman, konsep triangulasi, optimalisasi hasil, orientasi praktis dan keberlanjutan program (Rochdyanto, 2000).

Perencanaan partisipatif yang akan diterapkan dalam pendampingan penguasaan TPCK bagi guru-guru SD se gugus Kepatihan Kabupaten Kebumen, dapat dilihat dari peran serta masyarakat dalam perencanaan partisipatif yang dilakukan berupa: a). Hubungan yang saling mendukung antar guru-guru SD kelas tinggi dan rendah, b) guru-guru SD diberi kesempatan untuk menyatakan permasalahan yang dihadapi dan gagasan-gagasan untuk meningkatkan pembelajaran.

Prosedur PKM kepada guru-guru SD se gugus Kepatihan Kabupaten Kebumen melalui 3 tahap yaitu a) partisipasi dan sosialisasi, b) Pelatihan dan penggunaan media pembelajaran, c) pendampingan dan monitoring berkelanjutan. pelaksanaan dan tahap evaluasi.

a. Tahap partisipasi dan sosialisasi (identifikasi produk dan sosialisasi)

Aktivitas dengan mensurvai lokasi untuk pelaksanaan PKM dan mengurus surat perijinan kepada kepala sekolah. Kemudian mempersiapkan materi pelatihan, membuat contoh produk simbolis misalnya media online PHET Simulation. Selanjutnya koordinasi dengan guru SD untuk sosialisasi tentang penguasaan Technologi, Pedagogical, Content Knowledge (TPCK). Penyuluhan Dengan metode ceramah untuk menyampaikan materi sajian oleh penyaji. Penyajian diberikan secara ringkas dengan menggunakan LCD. Sebagai pendahuluan disajikan meteri tentang penyuluhan tentang TPCK dilanjutkan dengan tanya jawab. Pada tahap ini diamati dengan lembar observasi, wawancara dan angket untuk melihat respon masyarakat.

b. Tahap pelatihan dan penggunaan media pembelajaran (praktek dan pendampingan)

PKM dilaksanakan selama 4 kali pertemuan yang terdiri dari:

Tahap I: Penyuluhan tetang literasi TPCK

Tahap II: Penyuluhan dan pendampingan Penggunaan Google PHET Simulation sebagai media pembelajaran. 
Tahap III: Penguatan materi IPA,Matematika, dan bahasa Indonesia yang menjadi permasalahan di SD.

Tahap IV: Pembuatan soal berbasis HOTs pada mata pelajaran SD.

c. Tahap pendampingan dan monitoring berkelanjutan

Tahap monitoring dan evaluasi bertujuan untuk mengetahui seberapa besar peningkatan kompetensi guru dalam pengetahuan TPCK. Hasil yang diobservasi dianalisis secara kualitatif dalam inovasi pembelajaran dimasa pandemic covid 19.

d. Tahap Evaluasi dan Refleksi

Evaluasi dan refleksi dilaksanakan untuk melihat kelemahan dan kelebihan kegiatan pendampingan TPCK bagi guru SD di Kebumen.

\section{HASIL DAN PEMBAHASAN}

Pendampingan literasi TPCK dilaksanakan dengan tahap perencanaan, pelaksanaan, evaluasi, dan refleksi. Pada tahap perencanaan diawali dengan menyusun materi, jadwal pelaksanaan, dan menghubungi ketua gugus di SD Kutosari 1. Kegiatan pengabdian masyarakat tentang pendampingan TPCK rencana dilaksanakan selama 4 kali pertemuan namun karena adanya wabah pandemic covid hanya dapat dilaksanakan 2 x tatap muka dengan menerapkan protokol kesehatan yang ketat. Peserta diwajibkan mengenakan masker, cuci tangan, dan diukur suhu badannya sebelum masuk ruangan. Setelah sampai ruangan peserta duduk berjarak dan tidak diperbolehkan untuk saling berbicara (Gambar 1).

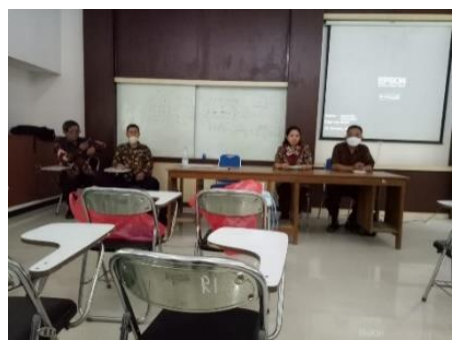

a.

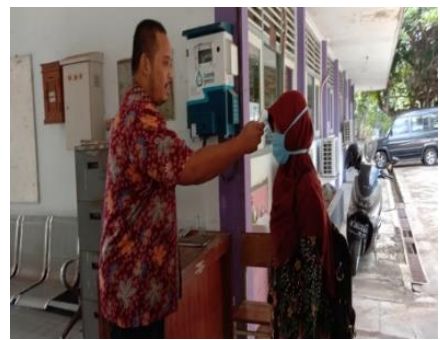

b.

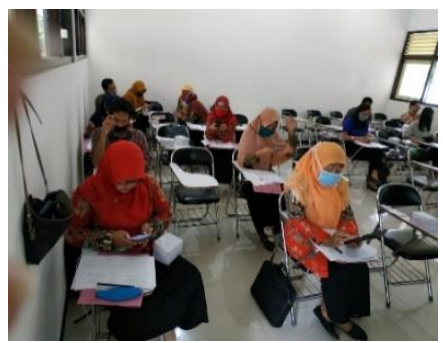

c.

Gambar 1.a. Pengukuran suhu, b. peserta guru SD, c. tim P2M PGSD Kebumen

Pada tahap evaluasi dan refleksi diminta para peserta mengungkapkan kendala-kendala selama menerapkan TPCK. Materi disampaikan oleh anggota tim P2M sesuai dengan bidang keahliannya (Tabel 1).

Tabel 1. Materi dan Pemateri Literasi TPCK

\begin{tabular}{lll}
\hline No & Materi & Pemateri \\
\hline 1. & Literasi TPCK & Dr.Kartika Chrysti S.,M.Si \\
& & Dr.Rokhmaniyah.,M.Pd \\
\hline 2. & Penguatan materi IPA & Dr.Kartika Chrysti S.,M.Si \\
\hline 3. & Penguatan materi Matematika & Drs.Wahyudi.,M.Pd \\
\hline
\end{tabular}




\begin{tabular}{lll}
\hline & & Drs.Joharman.,M.Pd \\
\hline 4. & Penguatan materi Bahasa Indonesia & Dr.Rokhmaniyah.,M.Pd \\
\hline 5. & Penguatan materi IPS & Drs.M.Chamdani.,M.Pd \\
\hline 6 & Aplikasi google phet simulation & Siti Fatimah.,M.Pd \\
\hline
\end{tabular}

Aktivitas evaluasi dan refleksi dilakukan secara daring dengan bantuan aplikasi whats up grup (WAG). Pelaksanaan terdiri dari pendampingan pedagogical knowledge, content knowledge dan technological knowledge.

a. Pelaksanaan Pendampingan Pedagogical Knowledge

(1) perencanaan pembelajaran, (2) pengorganisasian pembelajaran, (3) pelaksanaan pembelajaran, dan (4) pengawasan / evaluasi pembelajaran. Hasil pengujian pengukuran dengan analisis faktor menunjukkan bahwa keempat indikator tersebut siginifikan untuk menjelaskan variabel manajemen pembelajaran. Review materi pedagogical knowledge tentang implementasi kurikulum 2013, penerapan model dan metode pembelajaran, serta penilaian autentik. Pelatihan dilakukan dengan metode ceramah disertai tanya jawab. Berdasarkan wawabcara pada beberapa peserta kendala muncul karena tidak semua peserta mampu menerapkan inovasi model pembelajaran. Pada umumnya mereka hanya menyampaikan materi kemudian peserta didik mencatat, karena dikejar target harus selesai menyampaikan materi.

b. Pelaksanaan Pendampingan Content Knowledge

Tujuan pendampingan content knowledge untuk guru profesional adalah: 1) agar guru SD menguasai materi 5 mata pelajaran untuk menghindari miskonsepsi, 2) untuk meningkatkan kemampuan mengkomunikasikan pengetahuan pada peserta didik, 3) meningkatkan kualitas kinerja guru dalam keterampilan mengajar, 4) meningkatkan kepercayaan diri dalam mengajar. Peserta antusias dan semangat untuk mengikuti pembekalan. Pendampingan content knowledge diberikan pada materi yang sering menimbulkan miskonsepsi bagi peserta didik (Tabel 2).

Tabel 2. Penguatan Materi Lima Mata Pelajaran di SD

\begin{tabular}{lll}
\hline No & Mata Pelajaran & \multicolumn{1}{c}{ Materi } \\
\hline 1. & PKn & - Hak asasi manusia \\
& & - Persatuan dan kesatuan dalam keberagaman \\
& masyarakat \\
& & - Konsep nilaii, moral dan norma \\
& & - Pancasila dan kewarganegaraan global \\
\hline 2. & IPA & - Metode ilmiah \\
& & - Hidup sehat \\
& & - Metabolisme (anabolisme dan katabolisme) \\
& - Rangkaian listrik terbuka dan tertutup \\
\hline
\end{tabular}




\begin{tabular}{lll}
\hline 3. IPS & - Manusia, tempat dan lingkungan \\
& - Waktu perubahan dan system social budaya \\
& - Perilaku ekonomi dan Kesehatan \\
& - Fenomena interaksi dalam perkembangan \\
& IPTEK dan masyarakat global \\
& & - Volume bola \\
& - Statistika dan peluang \\
& - Geometri dan pengukuran \\
\hline 4. Matematika & Bahasa Indonesia & - Ragam teks dan satuan Bahasa pembentuk \\
& teks \\
& - Kalimat pokok dan kalimat penjelas \\
& - Struktur fungsi dan kebahasaan teks fiksi \\
& - Apresiasi karya sastra anak \\
\hline
\end{tabular}

Kendala dalam pelaksanaan kegiatan ini adalah ternyata terdapat beberapa peserta yang mengalami miskonsepsi dan tidak paham konsep pada materi lima mata pelajaran di SD. Miskonsepsi yang terjadi misalnya pada materi IPA tentang hubungan proses anabolisme dan katabolisme pada peristiwa respirasi dan fotosintesis. Kemudian pada mata pelajaran IPS, konsep produksi, konsumsi dan distribusi, hakekat tempat dan hakekat lingkungan.

c. Pelaksanaan Pendampingan Technological Knowledge

Workshop (TK) dilaksanakan 26 Juni 2020 dengan cara diskusi dan pelatihan teknologi cara menggunakan google phet simulation. Kegiatan diikuti 18 orang guru dari gugus SD di Kebumen. Peserta mengikuti kegiatan melalui protokol kesehatan yang ketat. Kegiatan diawali dengan penyampaian materi dengan metode ceramah dilanjutkan dengan tanya jawab dan pelatihan google phet simulation.

Tujuan pendampingan TK adalah; 1) memberikan paradigma baru tentang inovasi media pembelajaran online di masa pandemic covid 19, dan 2) meningkatkan keterampilan menggunakan media pembelajaran on line, dan 3) meningkatkan kreativitas guru SD dalam merancang RPP dengan menerapkan media pembelajaran online.

Semua peserta terlibat aktif untuk mengaplikasikan google phet simulation untuk mata pelajaran Sains (Fisika, Biologi, Kimia, Bumi dan Antariksa). Untuk tahap pertama tim P2M menerapkan menggunakan aplikasi pada mata pelajaran IPA Fisika. Tim Riset Grup (RG) Pendidikan dan Kewirausahaan terdiri dari 5 anggota dengan bermacam bidang keahlian. Anggota tim berkeliling untuk mengajari peserta cara menerapkan google phet simulation materi konduktor dan isolator. Aplikasi diterapkan dengan beberapa tahapan yaitu membuka website google, pilih 
phet colorado.edu, selanjutnya peserta dapat memilih aplikasi materi sains yang akan diajarkan ke peserta didik (Gambar 2).
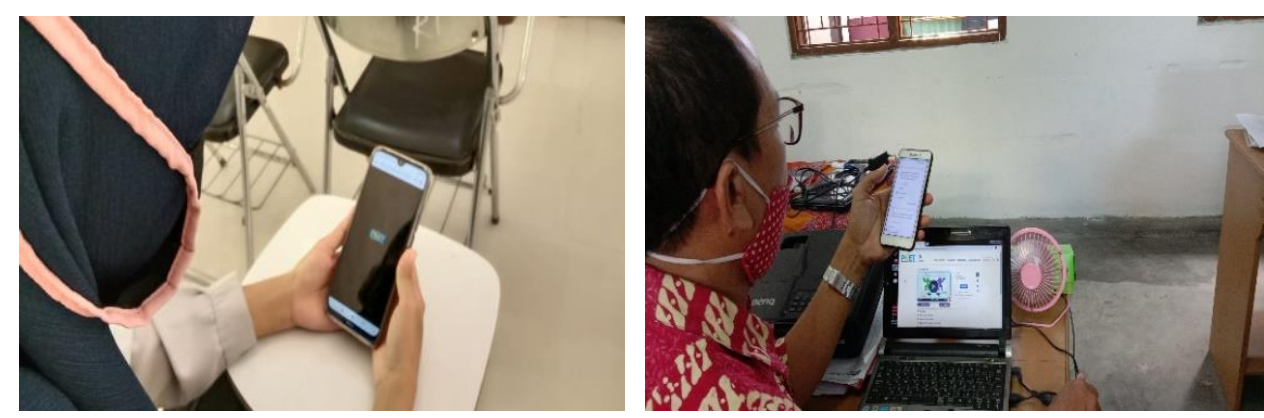

Gambar 2. Peserta mengaplikasikan google phet simulation dengan bimbingan tim P2M RG Pendidikan dan Kewirausahaan

Berdasarkan observasi ternyata semua peserta belum pernah mengaplikasikan google phet simulation, sehingga tim P2M harus bertahap dalam penyampaian agar dipahami peserta. Peserta mencoba aplikasi tersebut dengan antusias dan senang, dan menyatakan dapat diterapkan dalam pembelajaran di SD. Refleksi pendampingan TPCK mendapatkan dari respon peserta yaitu : 1) Merasa senang dan antusias mendapatkan ilmu baru yang dapat diterapkan sebagai media pembelajaran online, 2) membutuhkan pendampingan TPCK berkelanjutan, 3) kepercayaan diri guru semakin meningkat ketika memberikan materi pelajaran, 4) guru-guru harus lebih kreatif dan inovatif dalm mengajar dimasa paandemi covid 19.

\section{SIMPULAN DAN SARAN}

Berdasarkan pendampingan TPCK bagi peningkatan kompetensi guru maka dapat disimpulkan sebagai berikut:

1. Kegiatan pendampingan TPCK berlangsung dengan baik dan peserta merasa senang, antusias karena mendapat pengalaman baru mengikuti aktivitas sampai selesai.

2. Faktor pendorong pelaksanaan pendampingan TPCK tersedianya dana, sarana dan prasarana yang memadai serta kedisiplinan peserta dalam mengikuti kegiatan.

3. Faktor penghambat pelaksanaan pendampingan TPCK yaitu tidak semua peserta menguasai teknologi internet dengan baik.

4. Pelatihan dan pendampingan yang berkelanjutan secara intensif dapat meningkatkan kompetensi guru.

Adapun saran dari pendampingan TPCK adalah

1. Bagi guru agar lebih kreatif dan berinovasi menerapkan model dan media pembelajaran khususnya di masa pandemic covid 19. 
2. Bagi sekolah, memfasilitas sarana dan prasarana untuk kegiatan pendampingan TPCK berkelanjutan.

3. Bagi UPTD, memprogramkan pendampingan TPCK dalam kegiatan KKG guru agar lebih maksimal.

4. Bagi Dinas Pendidikan bekerja sama dengan perguruan tinggi untuk memberikan workshop dan monitoring berkelanjutan untuk meningkatkan kompetensi guru

\section{DAFTAR PUSTAKA}

Afandi \& Sajidan (2017). Stimulating Keterampilan Berpikir Tingkat Tinggi: Konsep dan Implementasinya Dalam Pembelajaran Abad 21. (Stimulating Higher Order Thinking Skill: The Concept and Its Implementation in 21st Century Learning). Surakarta: UNS Press.

Jimoyiannis A. 2010. Designing and implementing an integrated technological pedagogical science knowledge framework for science teachers professional development. Computers And Education 55 1259-1269. www.elsevier.com

Mishra,P,\& Koehler.M.J. 2006. Tecnological pedagogical content knowledge: A framework for integrating technology in teacher knowledge. Teacher CollegeRecord, 108(6), 1017-1054

Schneider,R.M and Plasman,K. 2011. Science Teacher Learning Progression: a Review of science teachers' pedagogical contein knowledge development. Review of Educational Research 81, 530-565

Shulman,L . 1986, Those Who Understand: Knowledge growth in teaching. Educational Researcher, 15 (2), 4-14

Shulman,L.S. 1987. Knowledge and Teaching; Foundation of The New Reform. Harvard Educational Review, 57 (1) 1-22 